\title{
Making sense of the anger of the Gilets Jaunes
}

\author{
Sarah Dubuffet ${ }^{1}$
}

\begin{abstract}
While most experts attempt to understand the Gilets Jaunes by establishing the causes of their anger, this paper studies this unprecedented mobilisation by focusing on the anger the protesters express. Their anger is examined by analysing four discursive examples of this feeling through the conceptual framework developed by Koenis. This framework makes a distinction between two types of anger: the anger expressed by the man of ressentiment and the rebel, respectively depicted by Dostoyevsky and Camus. The academic relevance of this paper not only lies in its attempt to bring emotions back into the study of protest but also to reconsider these two ideal frames of anger. The societal relevance, on the other hand, lies in that it depicts the anger of the Gilets Jaunes as being a complex combination of the two frames. This new perspective enables to understand the nuances of anger which drives the protesters rather than just reducing the GJ's mobilisation as a bare manifestation of this feeling.
\end{abstract}

\section{Introduction}

Since October 2018, an unprecedented form of mobilisation has spread across France. The Gilets Jaunes phenomenon has surprised politicians, journalists, experts and citizens due to its scope and spontaneity. This mobilisation initially emerged from calls on social media to demonstrate against the augmentation of fuel price due to an increase of the Taxe Intérieure de Consommation sur les Produits Energétiques [Internal Consumption Tax on Energy Products, hereinafter TICPE]. Since September 17, the Gilets Jaunes (hereinafter GJ), deriving their name from their rallying clothing symbol, a yellow vest, have submerged French streets every Saturday and blocked roads and roundabouts the remainder of the week to protest against excessive taxation. Due to the increasing pressure maintained by the mobilisation, the French executive power renounced the TICPE's rise at the beginning of December.

Despite this announcement, protesters have continued mobilising and have started to denounce other discomforts resulting from State's measures, e.g. lack of representative democracy, decrease of purchasing power, fiscal inequality, insufficient labour, and pension benefits. Visibly, the GJ have exclusively justified their mobilisation by their anger towards the established political system and its measures. To express this anger, the GJ have not only persisted in organising road blockades and Saturday's demonstrations, called Actes [Acts], but they have also posted videos on YouTube, or created online petitions, Facebook groups, and websites such as La France en Colère [Angry France].

As they aim to challenge the French political system, the GJ distinguish themselves from traditional protests by being voluntarily unstructured. In practice, it means that they refuse to designate official spokespersons, they dismiss any correlation with political parties or trade unions, and they do not

\footnotetext{
${ }_{1}$ Sarah Dubuffet received a bachelor degree in European Studies at Maastricht University in 2019. At the moment she takes a Master in International Politics at Katholiek Universiteit Leuven. Contact: sarah@dubuffet.eu
} 
want to establish any commonly agreed revendications. These singular characteristics establish an unprecedented and unpredictable form of protest, which presents the anger of the GJ as being the main reason and the only certainty of their mobilisation.

Several scholars have attempted to establish the causes of this anger from economic, political, anthropologic, historic, geographic and social perspectives (e.g. Béhar \& Delpirou, 2018; Bouloque \& Garrigues, 2018; Dubet, 2018). They, therefore, intend to answer the question: Why are the GJ angry? The responses vary from causes related to protesters themselves, i.e. identity, social class, living conditions, to causes regarding the society in which they live, i.e. political leadership, consequences of the 2008 financial crisis, and globalisation.

Although experts have started to understand the causes of GJ's anger, they have still not attempted to make sense of it. In other words, they have not yet focused on GJ's anger but rather what causes it. Therefore, this paper aims to fill this gap by examining the research question: How to make sense of the anger of the Gilets Jaunes? While looking at the causes of anger implies considering that all GJ depict the same kind of anger, making sense of this feeling rejects this simplistic approach and rather demonstrates that GJ's anger is nuanced. By grasping the complexity of GJ's anger, one can better understand the mobilisation. This study demonstrates that one can make sense of this anger through the conceptual framework elaborated by Koenis (2016). This framework distinguishes between two ideal types of anger: the man of ressentiment type depicted by Dostoyevsky and the rebel type depicted by Camus. This paper analyses four examples of discursive anger expressed by the GJ through the lens of this framework. The relevance of this study is mainly societal as it enables those citizens, journalists, and politicians, who tend to consider the GJ as only being a crowd of angry people, to better understand the mobilisation. Especially for politicians, this new insight can help them to design measures in line with the message the GJ want to convey by mobilising. Besides, the academic relevance of this paper not only lies in its attempt to bring emotions back into the study of protest but also to reconsider the two ideal frames of anger.

This paper commences with a literature review about anger and the GJ. The following section establishes the conceptualisation of the GJ, and the two ideal frames of anger depicted by Camus and Dostoyevsky. Then the similarities, differences and limitations of the frames are exposed, as suggested by Koenis. Afterwards, the main part analyses the four examples of discursive anger expressed by the G] through the conceptual framework. Finally, the last section concludes the analysis and provides a summary of the findings.

\section{Literature Review}

\subsection{Understanding the GJ; an emerging debate}

As the GJ's mobilisation is a current and unprecedented phenomenon, the academic debate is only starting. Noticeably, the existing debate on the GJ involves anyone concerned with the mobilisation; from the GJ themselves to journalists or politicians, rather than exclusively academics or experts. The debate is mainly fuelled through social media, websites, newspapers, magazines, and radio or television interviews. Therefore, instead of talking about a literature review, it is more appropriate to speak about a review of the general debate about the GJ.

It is commonly agreed that the GJ confuse and challenge all fields. This argument relies on the considerable variety of fields involved in the debate. Some books outline this variety by publishing

\footnotetext{
$2 \mid$\begin{tabular}{l|l} 
Marble \\
Research \\
Papers
\end{tabular}
} 
collection of philosophic, artistic, economic, social, geographic, and political analyses such as Le Fond de I'Air est Jaune [The air's background is yellow] (Monod, et al., 2019) and "Gilets Jaunes, Hypothèses sur un movement" [Gilets Jaunes, Hypotheses on a movement] (Bourmeau, 2019). All these fields seriously examine the GJ because they cannot find a straightforward explanation for this mobilisation, which defies all existing classifications (Silberzahn, 2018).

Up until now, besides contributions regarding the causes of the mobilisation, the debate is composed of hypotheses on the future of the GJ (e.g.,Ferry, 2019; Onfray, 2019; Pelluchon, 2019; Zaoui, 2019), discussions on the role of modernity, deindustrialisation and globalisation (e.g., Epstain, 2019; Ferro, 2018), the identity of the GJ (e.g. Giblin \& Sawicki, 2018; Lévy \& Dubet, 2018), and historical comparisons with Jacqueries ${ }^{2}$, the French Revolution or May 68 (e.g., Biard, 2018; Morin, 2019; Noiriel 2018 \& 2019). The marking facts of the mobilisation such as its spontaneity and persistence, the violence against journalists and policemen, and the propensity of the G] to propagate fake news, are also intensively discussed (e.g., Heyer \& Pigalle, 2018; Le Cain, 2018).

\subsection{Understanding anger; a long-standing debate}

Since Antiquity, renowned figures have attempted to understand anger. For instance, Plato in Republic, Seneca in De Ira, Aristotle in the second book of Rhetoric, and more recently, Sloterdijk in Rage and Time. As anger has been largely studied from different perspectives, it does not have any precise definition. Therefore, this paper relies on the broad definition by Holmes who, in her review about the political importance of anger, summarises that "anger is something recognised as a response to perceived injustice" in a relational interaction influenced by social and political circumstances (2004, p.123).

Regarding the GJ, the social and political circumstances refer to the general democratic system. The linkage between democracy and anger constitutes an important part of the literature about anger. While some scholars state that democracy initially neutralises anger through deliberation (Lacroix, 2019, p.47), others argue that democracy intrinsically fosters anger. One of the forerunners of this argument is Tocqueville who, in Democracy in America, explains that democracy and the consequent search for equality trigger different types of anger. In the same line of thought, Ter Braak considers that the fulfilment of democracy and equality facilitates resentment and he illustrates this argument with the triumph of National Socialism in the 1930s (as cited in Koenis, 2016, p.41). Koenis, who elaborated the conceptual framework guiding this paper, follows these arguments. In his book about anger and rightwing populist parties in the Netherlands, he demonstrates that citizen's anger and the existence of these parties result from the increasing democratisation of Dutch politics. However, he states that they do not necessarily pose a threat to democracy (Koenis, p.10).

To understand this paper's conceptual framework, it is important to understand the difference between resentment and ressentiment (from French). Anger and resentment refer to the same idea, while ressentiment is a specific subcategory of this concept. Ressentiment is a notion elaborated by the philosopher Scheler, himself inspired by Nietzsche and Dostoyevsky. As ressentiment does not have equivalent in English, there is confusion between ressentiment, as depicted by Scheler, and resentment,

\footnotetext{
2 Peasants revolt against nobility in France during the 14th century
} 
which refers to the broad category of anger. Subsequently, when this paper mentions ressentiment, it refers to Scheler's concept which he defines as:

"A self-poisoning of the mind which has quite definite causes and consequences. It is a lasting mental attitude, caused by the systematic repression of certain emotions and affects which, as such, are normal components of human nature. Their repression leads to the constant tendency to indulge in certain kinds of value delusions and corresponding value judgments. The emotions and affects primarily concerned are revenge, hatred, malice, envy, the impulse to detract, and spite" $^{\prime \prime 2007, ~ p .29) ~}$

The historian Ferro, who studies the historical patterns leading to resentment, approaches resentment as a manifestation of social anger which refers to both the ressentiment type of anger depicted by Dostoyevsky and the rebel type depicted by Camus (Ferro, 2007, p.198; Koenis, 2016, p.63). The point Koenis challenges in Ferro's reasoning lies in his approach to consider these two different forms as referring to the same resentment (Koenis, 2016, p.65). This is the reason why Koenis suggests sharply distinguishing between powerless ressentiment and rebellious anger. In the first chapter of his book, Koenis presents these two frames as ideal types through which civilians' social anger can be denoted. As this distinction is the one guiding this paper, it is further explained in the conceptualisation section.

This work contributes to both debates about anger and the GJ by merging them together. On the one hand, studying the GJ through Koenis' framework allows expanding the debate on the mobilisation by providing a new perspective which can make sense of their anger. On the other hand, applying Koenis' framework to the GJ allows testing and reconsidering the ideal types of anger depicted by Camus and Dostoyevsky

\section{Conceptualising the Gilets Jaunes and two ideal frames of anger}

\subsection{A conceptualisation of the Gilets Jaunes}

This paper does not define the mobilisation on the basis of statistics and survey. In that respect, Le Monde offers interesting data about the age, sex and working status of the protestors $(2018 ; 2019)$. Since it is difficult to establish a straightforward definition of the GJ, this paper rather follows MosnaSavoye's alternative of framing a definition of the GJ by answering the three following questions (2019): What are they? Who are they? What do they do?

\subsubsection{What are they?}

This paper supports Mosna-Savoye's suggestion to study the GJ as a whole (2019). Consequently, the term mobilisation appears to be appropriate. In sociology and politics, mobilisation is defined as "the process by which individuals or sections of society become active and organised towards social change" (Oxford English Dictionary). This definition is preferred to the one of movement because, when one refers to movement, there is a tendency to assimilate the GJ to social movements. However, the whole issue in describing the GJ as such precisely lies in the fact that they escape the established categories of social movements.

Although the definition of mobilisation falls closer to the GJ, it still needs to be nuanced. Firstly, to be qualified as a mobilisation the GJ must be "organised". However, as already mentioned in the

\footnotetext{
4 \begin{tabular}{l|l} 
Marble \\
Research \\
Papers
\end{tabular}
} 
introduction, the GJ are voluntarily unorganised. Although they are not traditionally organised in their structure, the GJ still fit the definition of mobilisation as they organise their actions through social media. Secondly, although it is difficult to determine what specific changes the GJ want to achieve since they do not want to have any official revendications, one cannot query on the fact that they want social change. To the question What are the GJ, one can answer that they illustrate the process of mobilisation in which individuals organise their actions through social media to achieve social change without, however, having commonly agreed-upon objectives

\subsubsection{Who are they?}

As rallying symbols help to create a collective identity, this paper aims to determine who the GJ through their yellow vests are. This symbol has several meanings. Firstly, it refers to the initial protestation against the price of fuel. Since yellow vests are used for road safety, the first protesters have taken this symbol because it refers to the lexical field of transport to denounce the TICPE's rise. Later the yellow vests have represented a protestation against the general political system and its measures. Secondly, it evokes the need to be seen in an unsafe environment. With their yellow vests, the GJ feel that they are now visible in the eyes of the State (Paoli as cited in Gogos and Turczyn, 2019). Finally, it represents the openness of the mobilisation as presumably everyone own a yellow vest.

In Le Fond de l'Air est Jaune, Balibar draws an analogy between the way one can interpret the GJ mobilisation and the use of the yellow vest: it is "the identification without the identity, the body without a face, the presence without a name" (as cited in Mosna-Savoye, 2019). In conclusion, to the question Who are the GJ, one can answer that they are citizens who disagree with State's measures and feel forgotten by those initially meant to represent them.

\subsubsection{What do they do?}

Their main action is to protest through revendications. From French, revendication is defined as an "action to openly claim what is considered to be a right or a due" (Dictionnaire de l'Académie Française). Generally, GJ's revendications concern their legitimacy in the political decision-making process, which the government tend to bypass. However, as aforementioned, one of the particularities of the GJ is that they do not want to have any official revendications. Therefore, there is a huge variety of revendications as each protester is free to claim what he wants. To the question What do they do, one can answer that the GJ protest through revendications to claim their legitimacy in the political decision-making process.

Following the indications of these three answers, one can conclude that this paper conceptualises the GJ as a mobilisation organised on social media, which is composed by people who feel forgotten by the political system and who generally claim, through diverse revendications, their legitimacy to participate in the political decision-making process.

\subsection{Two ideal frames}

This paper is guided by Koenis' suggestion to distinguish between Dostoyevsky's man of ressentiment and Camus' rebel as two different ideal frames of anger. This section identifies the major characteristics of both frames, contrasts them and warns about their limitations. 


\subsubsection{Dostoyevsky's man of ressentiment}

It is in the tormented Russia of the nineteenth century that Dostoyevsky published Notes from the Underground. The first part of the book is dedicated to the presentation of the imaginary narrator while the second part recounts the failed attempts of revenge he tries to take against an officer who humiliated him. The tone of this book is bitterly ironic and presented as an embarrassing monologue, which helps to steer concepts such as humiliation, deception, and envy. All these concepts inspired Nietzsche's conception of ressentiment which in turn forged Scheler's thought.

The present section focuses on the main characteristics of the man from the underground, later referred to as the man of ressentiment. The narrator introduces himself as nasty, jealous, resentful, powerless, and guilty of his unhappiness. The source of his envy and jealousy emerge from the fact that the other [the officer] is favored by nature with qualities that he does not, and presumably will never, possess. In his attempt to escape his sorrow, the man of ressentiment firstly tries to convince himself that he is superior to the other (2008, p.23). Then, as the narrator understands he is powerless and will never obtain the envied qualities, he experiences negative feelings. The only actions the man of ressentiment is able to undertake are his own flagellation and hurting people. He enjoys this suffering for him and the others and does not want it to stop: "I know better than anyone that it can only harm me and nobody else (...) these hostile feelings swarm me and urge me to burst out, but I do not let them go" (Dostoyevsky, 2008, pp.15-17).

As he is envious and jealous, his anger has nothing to do with a rightful ambition to put an end to injustice. Instead, it only aims to exalt the poisoning combination of sorrow and despair (Dostoyevsky, 2008, p.21). Eventually, the narrator thinks about revenge. According to him, there are only "stupid and bounded men" who can take revenge on a rightful basis; but as he knows he is only jealous and nasty, he is unable to find legitimacy in his revenge (Dostoyevsky, pp.33-34). However, as soon as the idea of revenge takes hold of him, he lives for anything else but this idea (Dostoyevsky, p.23). Revenge has become his new ideal and he is ready to wait for years to elaborate it, even though he knows that his actions could be more harmful to himself than the addressee.

\subsubsection{Camu's rebel}

One century after Dostoyevsky, Camus wrote The Rebel, an essay on Man in Revolt. Camus' obsession for revolt, not to be confounded with revolution, can be attributed to his attachment to the colonised Algerian people. This interest can be traced through his different works, still related to the Absurd thought, such as Caligula, The Myth of Sisyphus or his Carnets (II) to name but a few. This paper only focuses on The Rebel.

According to Camus, the rebel is the one who says no [to intolerable constraints] but even though he refuses, he does not renounce: he is also the one who says yes [to values and attempts to recover his dignity] (1951, p.27). In the French etymological sense, the rebel spins round: he was coping with a degrading situation and suddenly faces it. Camus compares it to a relationship between a slave and his master. The meaning of the yes lies in the fact that through his refusal to obey an order, the man also rejects his slave's condition. He, therefore, becomes aware of a brand-new identification, of which he is proud. This part of himself that he wants to be respected becomes his highest preoccupation that he is ready to protect, even at the expense of his own life. Regarding the no, Camus explains that it implies the existence of a limit and of an other who tends to overstep it. As there is a 
sensation that the other exaggerates, the rebel refuses the other's intolerable excess and feels that his no is rightful (1951, p.28).

The rebel does not revolt only for himself. He acts in the name of a value which, albeit confused, is felt by the rebel as being common to all men. For instance, the slave does not revolt only against his master but also against a world of slaves and masters (Camus, 1951, p.355). Therefore, revolt results from the process of the informed man who becomes aware of his rights and then spreads this knowledge to other men (1951, p.27). This aspect entails the development of sympathy and solidarity among men who identify with each other and gather in the same revolt (1951, p.31). This reasoning resulted in the famous citation "I revolt - therefore we are" outlining that the individual acts for the common good $(1951$, p.27). This strong sense of solidarity and humanity therefore firmly rejects harm and murder.

\subsubsection{Contrasting the man of ressentiment and the rebel}

The similarities between both frames are, first, the notion of an other who is superior to or felt as such by the man, and second, the notion that a limit has been overstepped by this other. Both men are devoted to their anger, which is a response to perceived injustice in a relational interaction, as explained by Holmes (2004). In a way, the fact that the other has overstepped a limit triggers the anger of the two frames.

Koenis' work (2016) usefully guides this paper in outlining the main differences between the ideal frames. Firstly, when the other has overstepped the limit, the source of their anger is different. The rebel's anger results from an understanding of his importance and rightfulness while the man of ressentiment's anger stems from his powerlessness. Moreover, according to Camus, at the source of revolt, there is a principle of abundant energy and activity, while at the source of ressentiment there is only envy and jealousy (p. 32). Secondly, the purpose of their anger is different. While the rebel undertakes rebellious effort to change an uncomfortable situation, generally to obtain emancipation, the man of ressentiment only undertakes rancorous efforts to express his anger without looking for suggestions of change. In other words, while ressentiment is a confinement of prolonged impotence which leads to self-poisoning of the mind, revolt helps the man to burst out and to free these toxic feelings (Camus, 1951, p.32). This implies that the rebel always gets good press. He is a striking model of justifiable anger or what would be positive anger with which everyone likes to identify, while the man of ressentiment illustrates what would be negative anger (Camus, pp.31-32; Koenis, p.13).

Another difference is the passive aspect of ressentiment, emphasised by Scheler himself (Camus, 1951, p.32), versus the active aspect of the rebel. Koenis argues that the main difference between the frames is that the rebel converts his anger into acts of change, while the man of ressentiment, for whatever causes, remains deprived of the acts that can put an end to his anger (2016, p.28). The last difference concerns the relation to oneself and others. While the man of ressentiment wants to be different and envy the other, the rebel defends his integrity and qualifies what he is as more important than what he could envy. Besides, the rebel accepts to suffer and to die for his revolt, but he does not wish harm to the others unlike the man of ressentiment who enjoys suffering.

Making sense of 


\subsubsection{Limitations of the ideal frames}

Although the man of ressentiment and the rebel are still clearly recognisable examples of social anger, they remain "ideal type" and it is important to nuance their applicability to contemporary events and meanings (Koenis, 2016, p. 16). Koenis makes two important remarks in that respect.

Firstly, in contemporary occidental societies, the rebel frame is distorted because the anger expressed would not be the result of a classical emancipation drive but rather a gathering of citizens who are afraid to lose their assets (Koenis, 2016, p. 26). Neither does the contemporary expression of anger accurately fit the frame of the man of ressentiment as it is not about powerless anger from which pleasure is drawn, "but an active, albeit highly individualised, response to everything that doesn't appeal to him in the outside world" (Koenis, p.27). Therefore, it is necessary to refine these frames depending on their case study and to create intermediate variants.

The second remark concerns the distinction between the reasonable rebel whose anger is justified and the unreasonable man of ressentiment whose anger is not justified. Koenis signals that this distinction oversimplifies the contemporary social anger dynamic. Moreover, he explains that scholars cannot establish what could or could not be qualified as reasonable or justified anger. If one makes the distinction between "reasonable revolt" and "unreasonable and powerless ressentiment" nuance, there is a risk of interpreting anger from the position of the winners (Koenis, 2016, p.16). Therefore, modern rebels who substantiate their claims by invoking justice and equality must recognise that their values are not absolute (Koenis, 2016, p.28).

There is an additional remark regarding the applicability of the frames. The purpose of this paper is to make sense of the type of anger expressed by the GJ. However, the conceptual frames do not implicitly refer to a certain type of anger but rather to angry persons, namely the rebel and the man of ressentiment. It is worth clarifying that this paper does not attempt to categorise the GJ as one or another frame of anger. Instead, it discusses the distinction between rebellious effort to change an uncomfortable situation and resentful efforts to only express anger without making suggestions for change.

\section{From theory to practice}

To make sense of the GJ's anger, four examples of discursive anger are analysed separately through the ideal frames. The accessibility to these examples was facilitated by the large amount of primary sources available on the Internet. The examples were all produced in French. The translation used in this work was made by the author who can provide a complete French and English version of the texts.

The examples were selected not only to assure the representativeness of GJ's anger, which as aforementioned is varied, but also the means used to express it. To illustrate this latter point, four different materials are analysed, namely video interviews, an online petition, a song, and a speech. Regarding the representativeness of GJ's anger, the selection criterion was that the material received important audience and support on social media, more particularly YouTube and Facebook, which are the main search engines. Since the mobilisation mainly spread through social media, this audience indicates that the example is not an isolated case but is shared by a greater part of the GJ. However, one must not forget that the mobilisation is unique in that it gathers different people with different objectives, and thus intrinsically, different nuance of anger. The examples, therefore, also reflect this diversity.

\footnotetext{
8 \begin{tabular}{l|l} 
Marble \\
Research \\
Papers
\end{tabular}
} 
Although blockades, violence and vandalism received strong coverage, this paper does not analyse these expressions as it rather focuses on discursive type of anger. They, nevertheless, remain relevant topics which are considered in the examples.

\title{
4.1 "In a way, Macron is my whore" - video interviews
}

4.1.1 Contextualisation and transcript

From the beginning of the mobilisation, non-professional and independent journalists have interviewed thousands of GJ and then posted their reportages on social media. Among the myriad of videos, one in which a young man compares the French President to a whore became particularly famous. This interview was filmed during Act IX, on January 2019 and has reaped approximately 45,000 likes, 121,496 shares and 5,700 comments on Facebook (Thibault, 2019 January 18). The interviewee is a young man named Thibault who reflects on the massive popular uprising, the police repression, and the low popularity rate of the French President Emmanuel Macron. Since the scathing sentences of this interview have been cut off from their contexts and published on social media, the complete interview, retrieved from the official website of the independent journalist who interviewed Thibault, was checked for authenticity (Le Média pour Tous). The following lines copy the relevant extracts of the interview (Les Gilets Jaunes Déterminés, 2019).

\section{[Extract 1]}

Macron, "the Savior of democracy", (...) is reprimanding the legitimate claims [revendications] of the people. Legitimate! When this guy [Macron] is calling me lazy - and is calling all of us lazy by the way this is completely sidesplitting! (...) This guy is useless, it is him the real parasite of the society, that's Macron! It has to be reemphasised: that's Macron! Me? It's my boss who pays me. Macron? I am the one who pays him. In a way, Macron is my whore!

\section{[Extract 2]}

We were promised a debate [Grand Débat National ${ }^{3}$ ] and we have received the counter-argument. That's not bad! (...) Actually, it was a debate with a Flash-ball on the temple [Lapierre's intervention] Yes, exactly! That's the idea! I think that it is a very democratic way of debating. That's great, that's great!

[Extract 3]

I also saw that policemen caught a guy, slaughtered him on the ground and then brought him back like everything was fine. It is a real pleasure, in the "Country of Human Rights". The man has just been caught, he did not even defend himself and then a guy [policeman] just came behind him and bang bang - bang! That's fine, really. No worries, that is just four or five punches in the face.

Due to the success of the first video, a second interview was entirely dedicated to Thibault to allow him to develop his opinions. It was slightly less famous than the first one, but is still relevant for this paper. The following lines transcribe five extracts from the thirty minutes long interview (Thibault, 2019 January 29).

\footnotetext{
3 Public debate launched by President Macron at the end of December 2018 to create a dialogue between the authorities and the GJ
}

\author{
Making sense of \\ the anger of \\ the Gilets Jaunes
}




\section{[Extract 4]}

I would like to make my sincere apologies. (...) With regard to ladies of the night, the prostitutes... It's true that no one appreciates to be insulted and to be called a Macron (...) I'm sorry, girls (...) So, I repeat it, I do not assimilate any whore to Macron!

\section{[Extract 5]}

I received a lot of support and sympathy from people who think about the same things as $I$. I think that it expresses a discomfort, a disapprobation, an anger towards the President of the Republic and institutions in general. This anger is shared and legitimate. This anger is illustrated through the GJ.

\section{[Extract 6]}

What the French people and I need to find with the GJ, is a sovereignty. We cannot pretend to be free when we are enshrined, we cannot pretend to be sovereign when our country does not belong to us. We cannot pretend to regain control as long as we remain in the shackles of the European Union, the shackles of the 5th Republic, and the shackles of this modern political life and not of finance. We cannot pretend to be free until we can get out of this. And I think the GJ can be a movement - where there will be difficult moments, there will be sacrifices and fights, it will be very hard - but I think the GJ have been the initiation of something. Of an important movement of the awakening of the French people.

\section{[Extract 7]}

There is resentment towards a certain part of the police. When you systematically see the police force using violence every week, this creates a certain resentment, we must not deny it. We must think in a smart way, let's put our legitimate resentment aside. Let's send a message to the policemen: Guys, you are part of us, you are not part of them.

\section{[Extract 8]}

The GJ represents all the diversity of the French people. Let's stop the classic game of parties, divisions, and politics. (...) Let's stop the quest of the more legitimate revendication. Let's stop finding leaders and determining if we like them or not etc. Let us manifest fraternally and rediscover this sense of the French fraternity as it is written in the Republican motto. Fraternity. The Fraternity of the French people whatever the parties or the opinions, whatever the quarrels of class, region or city, etc. Let us be a United French people against the anti-France. I think that is the message of the GJ.

\subsubsection{Analysis}

In this example, two others are identifiable: the political authorities and the police force. The formers have overstepped a limit by imposing intolerable political measures and by not considering neither respecting the GJ. This argument is supported by Extract 1: "he is repressing the legitimate claims of the people", and Extract 2 "we were promised a debate and we have received the counter-argument". On the other hand, the police force has overstepped a limit by enforcing an unprecedented violence against people during manifestations as mentioned in Extract 3 and 7: "when you systematically see the police force using violence every week, this is a certain resentment". In this example both frames' characteristics are present.

As the man of ressentiment, Thibault is ironic: "Macron, the Saviour of Democracy" (Extract 1), "That's not bad!" (Extract 2), "It's a real pleasure, in the Country of Human Rights", "No worries, that's

\footnotetext{
10 Research Papers
} 
just four or five punches in the face" (Extract 3), and "It's true that no one appreciates to be insulted and to be called a Macron" (Extract 4). However, despite this irony, his anger stems from an understanding of the man's importance and rightfulness, which is peculiar to rebel's efforts. He indeed outlines what he argues is unacceptable in the political system and the method of police force. As a result, he spreads this knowledge through the videos (Extract 5, 6, 8). In a way, through his irony he says no to the political authorities, their measures and the violence between the police and the people. Regarding this last point, the man does not only reject the violence against the GJ but also against the policemen and he calls for fraternity (Extract 7,8 ). This is typical to the rebel who rejects harm not only for him but for all men. Moreover, one notes that Thibault makes suggestion for change by requesting the $\mathrm{GJ}$ to put aside their resentment against the police (Extract 7).

Nevertheless, his attitude towards policemen is not replicated with political authorities. As shown in Extract 6, he criticises the European Union, the Fifth Republic, and the modern political system but does not suggest any concrete act for change. This reaction fits the contemporary man of ressentiment who expresses an "individualised response to everything that doesn't appeal to him on the outside world" (Koenis, 2016, p.27). Besides, he does the same for Macron. Since he has felt humiliated to be called "lazy" by Macron (Extract 1) and frustrated by the Grand Débat National (Extract 2), he criticises the President and wants him to be humiliated in turn (Extract 4). However, contrary to the man of ressentiment, Thibault does not envy the other. As Hegel, who makes the master dependent of the slave recognition (Koenis, 2016, p.13), the young man argues "I'm the one who pays him" (Extract 1). Since Thibault is aware of his importance, he repeats several times that GJ's anger is legitimate (Extract $1,5,6,7)$. We must however be careful when claiming that anger is legitimate or not (Koenis, 2016, pp. $16 \& 28)$.

All along the extracts, Thibault speaks on behalf of the GJ. He, therefore, finds a new identification in the mobilisation: "what the French people and I need to find with the GJ" (Extract 6) and "we have a common objective interest" (Extract 8). Furthermore, he promotes "the awakening of the French people" (Extract 6), "let us be a United French people against the anti-France" (Extract 8) which sounds as an emancipation act. Consequently, this anger does not fit the definition of the contemporary rebel who is afraid to lose his assets, but rather refers to the original meaning of the rebel (Extract 6). Therefore, his yes lies in the fraternity and the continuation of the GJ mobilisation as an attempt to recover dignity (Extract 6 and 8). Thibault's reasoning received good press on the social network and fosters solidarity among the GJ (Extracts 5 to 8 ).

In conclusion, both ideal frames are closely related in this example. On the one hand, the rebel says no to the others and their behaviour, and yes to the mobilisation as an attempt to find dignity. On the other hand, the contemporary man of ressentiment is reflected as Thibault only criticises the others without solutions for change, with the exception of policemen.

4.2 "A referendum on the RIC, the decline of taxes on basic necessities products, and the reduction of the representatives' salaries" - online petition

\subsubsection{Contextualisation and transcript}

Since the start of the mobilisation, hundreds of different petitions have flooded the Change.org petition website, e.g. petitions requesting scholars and artists to support the GJ, calling for the United Nations to 
investigate police violence, and demanding the mobilisation to stop. Long before the mobilisation, in May 2018, Priscillia Ludosky posted a petition requesting the reduction of fuel prices. Six months later, this petition coincided with the initial revendication of the GJ protesting the TICPE's increase. The text has gathered approximatively 1,245,015 signatures (Ludosky, 2018). Seven months after the publication of the petition, Marcon replied to Ludosky on the petition website. He stated that he understood the discontent of citizens and outlined some decisions taken in favour of them. Ludosky qualified this answer as hardly constructive.

Further to this unfruitful exchange, Ludosky created a second petition but this time she acted as a representative of the GJ's wishes. The petition, which has gathered 95,821 signatures, demands a national referendum on three demands: (1) the establishment of the Referendum d'Initiative Citoyenne ${ }^{4}$ [Citizen Initiative Referendum] (RIC), (2) a reduction of all taxes on basic necessities products (energy, housing, transport, food product, clothing), and (3) a significant reduction in all current and future pensions, salaries, privileges and pensions of the elected representatives and senior officials (Ludosky, 2019).

\section{[Extract 1]}

The National Commission of Public Debate (CNDP) was mandated to organise this debate [Grand Débat National]. The Commission invited us to participate in a meeting to present our subjects and to discuss the modalities of organisation. This meeting was cancelled following the resignation of Commission' President, Ms Jouanno, and the withdrawal of the CNDP from the general organisation of the debate. We had already mentioned it; we were wary of this debate but did not refuse to participate to it (...). While waiting for the government to organise, let's organise ourselves!

[Extract 2]

I only have a role in transmitting the needs expressed by many Gilets Jaunes. Together, we asked the

Government in Versailles, (...), to organise a referendum to ask French citizens their opinion on the creation of a text aimed to the implementation of these three claims. To date, we have not received any answer. This is why, through this petition, we ask your opinion. Are you or are you not for a referendum to be organised for the implementation of these three claims?

\section{[Extract 3]}

Article 6 of the Declaration of the Human and Citizens Rights of 1789, which is part of the preamble of our Constitution, provides for the participation of citizens in the creation of laws. It states: "Law is the expression of the general will. All citizens have the right to compete personally or through their representatives in its formation". This text has never been applied!

\section{[Extract 4]}

While elected representatives develop and vote laws, voters are excluded from the process. (...) As a result, today's mistrust of the French people towards the political class is unprecedented. It is therefore urgent to balance the system by instituting in our country the referendum for citizens' initiative [RIC]. (...) Only being allowed to slip a ballot in the ballot box to elect a president, a deputy or a mayor, is not the exercise of sovereignty. Instead, it is a dispossession and an obligation to keep silence for 5 or 6

\footnotetext{
4 The RIC refers to a decision-making procedure whose initiative exclusively belongs to citizens. If a predefined minimum number of citizens support a project, the executive power is obliged to create a national referendum to take a decision on that project (e.g. dismissal of representatives, change in the Constitution)

$12 \mid$\begin{tabular}{l|l} 
Marble \\
Research \\
Papers
\end{tabular}
} 
years. In a democracy, the people must be able to be the legislator of last resort. Only the RIC will allow us to take the floor at any time to decide what concerns us, and thus to fully become citizens.

\subsubsection{Analysis}

In this case, the State represents the other while the limits concern the participation in democracy, the price of taxes, and the salaries of the elected representatives. The present example is undoubtedly closer to the rebel type than the man of ressentiment type of anger.

Firstly, when one looks at the context of the second petition, it proves to be a reaction to Macron's disappointing response to the first petition. Instead of surrendering and conceding to ressentiment type of anger, Ludosky started the operation again with more concrete suggestions for change such as "to organise a referendum in order to ask French citizens their opinion on the creation of a text aimed to the implementation of these 3 claims" (Extract 2) and the implementation of the RIC (Extract 4). Even when the other does not cooperate for improvement by cancelling meeting or not replying to demands, she is determined to launch more actions for change: "while waiting for the government to organise, let's organise ourselves!" (Extract 1), "to date, we have not received any answer. This is why, through this petition, we ask your opinion" (Extract 3), "it is therefore urgent to balance the system" (Extract 4).

Through her petition, Ludosky highlights a strong notion of solidarity and community. Her actions are representative of, and beneficial for, all the GJ. She matches the idea that the rebel is a person informed of his rights who spreads his knowledge to the components of the community of solidarity: "this text has never been applied!" (Extract 3), and "the people must be able to be the legislator of last resort" (Extract 4). These claims gather a lot of signatures, which demonstrates the good press Ludosky's anger has received. Moreover, she uses first person plural during the whole petition as she does not speak for herself but for the GJ community and the new identification she has found among them: "I only have a role in transmitting the needs expressed by many Gilets Jaunes" (Extract 2). This match this sentence typical to the rebel "I revolt - therefore we are" which outlines the importance of individual action for the benefit of the community (Camus, 1951, p.27).

Secondly, Ludosky is proud to be a citizen as well as a GJ and she is not jealous of the other. She says no to the system which disregards her identity and diminishes the citizens' rights to fully participate to the functioning of the political activity (Extract 2 and 4). However, she says yes to alternatives which would improve the current uncomfortable situation experienced by citizens: "we were wary of this debate but did not refuse to participate" (Extract 1), "are you or are you not for a referendum" (Extract 2), and "only the RIC will allow us to take the floor at any time to decide what concerns us" (Extract 4). Moreover, by relying on law in Extract 3 she outlines the legitimacy of her arguments. However, one must remind Koenis' warning about the reasonableness of anger (2016, p.16).

In conclusion, this petition does not present a ressentiment type of anger as it is not an individualised action, there is not enjoying of the suffering, there is no jealousy regarding the other, and Ludosky converts her anger into acts for change. What is particular in this petition, is that it refers to the original meaning of the rebel type of anger and not to the contemporary rebel type suggested by Koenis (2016, p. 26). Indeed, Ludosky's efforts induce that she wants to achieve emancipation by taking the citizen back in political decision-making process (Extract 2 to 4 ).

Making sense of the anger of 


\section{3 "Gilets Jaunes" - song}

\subsubsection{Contextualisation and transcript}

From the start of the mobilisation, artists have not failed to create all sorts of songs about the GJ. D'Ace and Momo featuring Charley Dornel have written thoughtful texts reflecting on social fault lines and the importance to protest against injustice. Other artists such as Cagoule, have released covers or parodies of famous songs mostly targeting Macron, which are far less elaborated and meaningful. The present section analyses one of the songs produced by the rapper D1ST1. Released on January 20, the song "Gilets Jaunes" has reaped 27, 000 likes on YouTube (D1ST1, 2019). The official video of the song shows the rather chocking police violence against civilians during Act IX and some previous Acts in Toulouse.

[Extract 1]

The rage of the people, I see it every Saturday We are penniless, we don't have enough to fill a trolley (...) We move, we mobilise ourselves, that France gets organised Let everyone be in the streets and head for the Élysée We want to be able to create laws or to challenge them

[Extract 2]

And on Saturday, in the centre of the city, I'm pleased by all I see I see everyone getting organised even though everyone is in pain

I see all the people wearing helmets and gas masks (...)

On the other side, I see the police force (...)

They wait until we are all grouped together

And then they take the opportunity to gas us, even the elderly, even the children

[Extract 3]

When you find yourself standing there, standing right in front of the cops

And you see them bludgeoning people, how can you remain peaceful? And then, when you're in the midst of the protest and you see the cops putting on their gloves

Two minutes later, you see the bloody faces (...)

I have something to say to all the pacifists

If they are still staying peaceful, then they're not truly in the protests

I saw the guy next to me get shot with a Flash-ball right in his head

I see the blood of the yellow vests flowing, that's what bothers me

\section{[Extract 4]}

I take this opportunity to tell everyone not to give up

What we have launched has spread all over the world, you have to know

This is revolution, we're all out of control

Macron is like a matchstick, he's about to burn

Gilets Jaunes, what's your profession?

\subsubsection{Analysis}

This song can be divided into two dimensions. The first concerns the GJ's anger against the other [Macron] who has overstepped the limit to impose measures giving citizens a feeling of poverty and

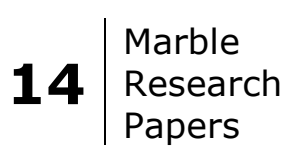


discomfort, as well as a sentiment of non-participation in law and politics. This anger is notable in Extract 1: "we are penniless, we don't have enough to fill a trolley", and "we want to be able to create our laws or to challenge them". Together with the GJ, the rapper says no to these situations by protesting during the Acts: "the rage of the people, I see it every Saturday" (Extract 1). Unlike the contemporary meaning of the rebel, the rapper is not afraid to lose his assets, but he wants his uncomfortable situation to change. Thus, the song rather refers to the classical meaning of the rebel who aims to achieve emancipation. However, except for protestations - "we move, we mobilise ourselves, that France gets organised" and "let us all be in the streets and head for the Élysée" (Extract 1) -, he does not suggest actions for change. Besides, he does not revolt for any above value common to all man as he wishes to overthrow Macron: "Macron is like a matchstick, he's about to burn" (Extract 5).

In the second dimension, the others are the policemen who have overstepped a limit by enforcing violent repression against protestors as evidenced by the following extracts: "they wait until we are all grouped together and then they take the opportunity to gas us, even the elderly, even the children" (Extract 2), "you see them bludgeoning people, how can you remain peaceful?" (Extract 3), and "I see the blood of the Gilets Jaunes flowing, that's what bothers me" (Extract 3 ). This second dimension is full of contradictions regarding the two ideal frames. The following sections move on to examine this complexity.

At first sight, one would like to argue that the song resembles the rebel type of anger for two main reasons. Firstly, the rapper knows he is rightful in rejecting violence against citizens, and secondly, he wants this argument to be known as he denounces injustice through a song. However, unlike the rebel, he wishes harm to others as he encourages violence and incites pacifists to be warmongers: "I have something to say to all pacifists, if they are still staying peaceful, then they're not truly in the protests", and "how can you remain peaceful?" (Extract 3). This incitement to violence is also exemplified through the reference to the film 300 Rise of an Empire ${ }^{5}$ : "Gilets Jaunes, what's your profession?" (Extract 4). By doing so, the rapper contrasts with the rebel who would fight for a value common to all men and reject harm. Another argument that sharply contrasts with the rebel, is that the rapper does not make any suggestions for change.

Consequently, one could then argue that this song is closer to the wicked type of anger expressed by the man of ressentiment. Firstly, it is the suffering of the rapper that makes him important in his song. Never in the text has he mentioned that he is proud of his identity and willing to fight to protect it. Instead, he sings that he is proud to fight, like if his willingness to act was only triggered by a reaction to violence. Curiously, he both denounces and encourages violence. Secondly, the rapper is aware that fighting against policemen will be more harmful for him than for them "I see all people wearing helmets and gas masks" (Extract 2), "you see the cops putting on their gloves, two minutes later, you see the bloody faces" (Extract 3). Nevertheless, he seems to enjoy this suffering as exemplified in Extract 2: "and on Saturday, in the centre of the city, I'm pleased by all I see, I see everyone getting organised even though everyone is in pain". Like the idea of revenge takes hold of the man of ressentiment, it seems that this willingness to fight takes hold of the rapper. Although this character seems only able to undertake resentful efforts to express his anger though violence, some

5 In the scene of the film, the leader Leonidas, to prove the superiority of his three hundred Spartan soldiers, asks them before fighting "Spartans, what's your profession". 
characteristics of the rebel type remain. For instance, the singer received good press on the social media for his song. Secondly, the rapper does not want to resemble the others.

In brief he says no to violence against citizens but says yes to violence against policemen. On the one hand, he wishes harm to the others, something that the man of ressentiment would do, but not the rebel. On the other hand, he seems wilful to be active like the rebel, but does not suggest any concrete solutions. He can only be active in violence and wickedness towards the others, like the man of ressentiment. Another contradiction is that the rapper's anger seems to take its roots in his understanding of rightfulness, but he also remains deprived of the act that can put an end to his anger. In other words, his anger is aimed at putting an end to an injustice, but he does so by encouraging violence and exalting anger with no concrete solution.

Instead of ending on a mixed note, this section attempts to explain the reason of this example's complexity. At the end of the song, the rapper claims "this is revolution, we're all out of control!" (Extract 4). This reference to revolution can explain the difficulty to analyse this song through the two ideal frames. In several of his works, most notably The Righteous and The Rebel, Camus studies the differences and linkages between revolt and revolution. More precisely, he wonders why revolution accommodates itself to murder and destruction when revolt affirms humanity and creation. Camus, in The Rebel, explains that the revolt gave birth to revolution and that, after having satisfied the spirit of revolt, revolution will deny this latter to fully assert itself (1951, p.359). Despite being related, these concepts imply contrary notions: revolt claims the unity of the human condition and creation, while revolution leads to destruction and murder (1951, p.356). Therefore, revolt, when it leads to destruction, is illogical (1951, p.356). Camus explains that when a rebel decides to support destruction, this decision that he expects to assert himself, actually destroys his identity of rebel (1951, p.352). In a certain manner, revolution is the perverted form of revolt. This clarification illuminates why the song was complex to be depicted in either ideal frame of anger. Indeed, the original anger of the rapper stems out from a spirit of revolt - he says no to violence - but it ended in a revolution - he enforces violence himself.

\section{4 "Call of the first Assembly of the Assemblies" - speech}

\subsubsection{Contextualisation and transcript}

At the start of the mobilisation, commentators have criticised the inability of the GJ to deliver clear messages and revendications. In response, the GJ's Assembly of Commercy organised a national meeting gathering a hundred of GJ's delegation from all across France to build commonly agreed bases. At the end of this meeting, called L'Assemblée des Assemblées [The Assembly of Assemblies], approximatively seventy people, each by each, read a speech which was recorded and posted on social media (Assemblée des Assemblées de Commercy, 2019).

\section{[Extract 1]}

Since November 17, from the smallest village, from the rural world to the largest city, we have risen up against this profoundly violent, unjust and unbearable society. We will not accept the situation passively!

We revolt against the high cost of living, insecurity and misery. We want to live with dignity for our loved ones, our families and our children. Twenty-six billionaires possess as much as half of mankind, that is unacceptable. Share wealth and not misery! Let's stop with social inequalities!

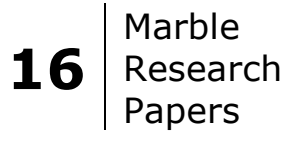




\section{[Extract 2]}

With our yellow vests, we take the floor, we who usually never take it. And what is the Government's response? The pressure, the contempt, the denigration. The deaths and thousands of wounded, the massive use of weapons that mutilate, put some people's eye out, hurt and traumatise. (...) We condemn violence against protesters as coming from law enforcement or violent groups. None of this will stop us!

\section{[Extract 3]}

After having insulted us and treating us less than nothing, now he [Macron] describes us as a hating and xenophobic crowd. Actually, we are quite the opposite: neither racist, nor sexist, or homophobic. We are proud to be together with our differences to build a united society. The diversity of our discussions makes us strong.

\section{[Extract 4]}

We call for the formation of committees (...). Let's take charge of our business! Don't stand alone, join us! Let us organise in a democratic, autonomous and dependent way! This Assembly of Assemblies is an important step that allows us to discuss our claims and means of action. Let us federate ourselves to change our society!

\subsubsection{Analysis}

In this last example, the other is the government and the limits are "high cost of living, insecurity and misery" (Extract 1). This speech matches the rebel type of anger in several respects. Firstly, the GJ say no and aim to put an end to injustice as exemplified in the whole Extract 1: "we have risen up against this profoundly, violent, unjust an unbearable society", "we revolt against", and "Let's stop with social inequalities!". Besides, they say yes to "live with dignity for our loved ones (...) and to "share wealth and not misery!". In addition to this last sentence, they add "twenty-six billionaires possess as much as half of mankind, that is unacceptable!". These arguments outline that the GJ act for an above value common to all men. This defence of humanity is also outlined in Extract 2: "we condemn violence against protesters as coming from law enforcement or violent groups.". Despite the Government's aggressive responses, this extract discourages the GJ to use violence.

Unlike the man of ressentiment, they wish to actively undertake change to undermine their uncomfortable situation: "we will not accept the situation passively" (Extract 1), "Let's take charge of our business! Don't stand alone, join us!", "Let us federate ourselves to change or society" (Extract 4). As the rebel, the GJ of this assembly spin round: "we take the floor we who usually never take it" (Extract 2). Now that they have made their no and yes heard, this claim has become their main raison d'être: "None of this will stop us" (Extract 2). Moreover, they suggest concrete measures of change through Extract 4: "we call for the formation of committees", "this assembly is an important step that allows us to discuss our claims and means of action". Obviously, these arguments received good press on the social media.

In addition to these points, the speakers are aware and proud of what they are: "actually we are quite the opposite, neither racist, nor sexist, or homophobic", "we are proud to be together with our 
differences". This implies a strong feeling of community and solidarity: "Let us federate ourselves to change our society" (Extract 4).

In conclusion, the anger expressed in this speech is typical to the rebel anger. However, the text still presents two specificities. First, once again, the rebel anger seems to take its classical sense of emancipation. Second, this text is the result of common work and not an individual. Therefore, the sentence "we revolt, therefore we are" fits better this example.

\section{Conclusion}

This paper aims to enlighten on the way one can make sense of the GJ's anger by investigating the research question How to make sense of the anger of the Gilets Jaunes? This study demonstrates that one gains new insight on the mobilisation by analysing four examples of discursive anger through the conceptual framework developed by Koenis, which allows to distinguish between two ideals frames of anger depicted by Dostoyevsky and Camus, respectively the man of ressentiment and the rebel.

Let us first regard the insight we gain about the GJ's anger. Instead of studying the causes, this paper focuses on the GJ's anger in itself. This paper demonstrates that GJ's anger must be nuanced and considered as a complex combination of two ideal frames. Consequently, by grasping the complexity of this feeling, one can better understand the mobilisation. Thanks to this new approach, politicians could take decisions closer to GJ's revendications, while journalists and outsiders could stop making the usual mistake to reduce the $\mathrm{GJ}$ as a bare manifestation of this anger without trying to understand it. In other words, this approach not only contributes to bringing a new perspective on the mobilisation, but it also allows demonstrating that GJ's anger must not be regarded as a bare expression of anger.

As a second contribution, this paper also helps to reconsider the two ideal frames of anger. Firstly, the G] case study confirms the validity of these frames. Secondly, only two others appear in the examples: the political authorities and the policemen, while the limit regards respectively political measures and violence. In all examples, the GJ say yes to the mobilisation as an attempt to recover their dignity. However, Examples 4.1 and 4.3 are less close to the rebel's characteristics than Examples 4.2 and 4.4 are. Regarding the rebel type of anger, none of the examples fit the contemporary rebel depict by Koenis as a man afraid of losing its assets, but rather refer to the classical meaning of the rebel, which implies that the GJ aims to gain emancipation from the State. Concerning the man of ressentiment, Example 1 is nuanced while Example 4.3 fits the description of the contemporary man of ressentiment who criticises everything that does not appeal to him in the outside world, without suggesting action for change. However, as we have seen this example is particular as it presents characteristics and the man in revolution type of anger.

Further research could develop this notion of revolution depicted by Camus. It could expand Koenis' conceptual framework from two to three types of anger. Moreover, it would be interesting to examine if the rebel characteristics examined in these extracts later present the revolution's characteristics.

\footnotetext{
$18 \mid$\begin{tabular}{l|l} 
Marble \\
Research
\end{tabular} Papers
} 